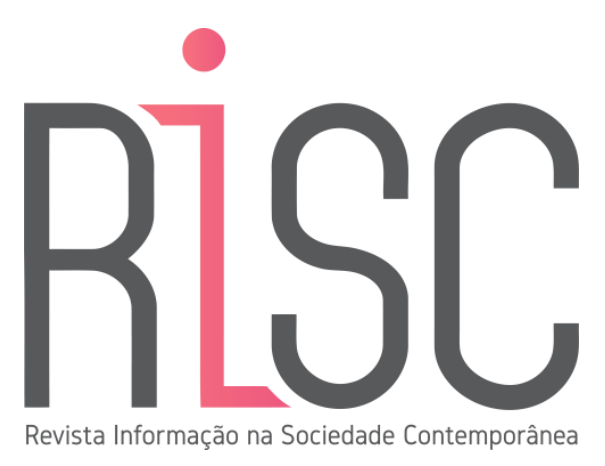

\title{
GESTÃO DA INFORMAÇÃO DE CONVÊNIOS ENTRE UNIVERSIDADES E FUNDAÇÕES DE APOIO À PESQUISA
}

\author{
Edilaine de Azevedo Vieira* \\ Mestranda em Gestão da Informação \\ https://orcid.org/0000-0002-7308-8870 E-mail: edilaineazevedo@ufpr.br
}

\section{Taiane Ritta Coelho*}

Doutora em Administração

https://orcid.org/0000-0003-2607-0704 E-mail: taianercoelho@gmail.com

* Universidade Federal do Paraná, Programa de Pós-Graduação em Gestão da Informação, Departamento de Ciência e Gestão da Informação, Curitiba, PR, Brasil.

\section{RESUMO}

Diante de um cenário de crise econômica e verbas cada vez mais escassas para a educação e projetos de extensão e pesquisa, este trabalho visa investigar por que as Universidades devolvem parte dos recursos provenientes de convênios firmados com as agências de fomento à pesquisa e extensão. Tem como objetivo geral analisar as causas para a devolução dos recursos recebidos via convênios, especialmente das Universidades Públicas do Paraná com a Fundação Araucária. Quanto ao método, será uma pesquisa qualitativa de caráter exploratório. Pretende-se realizar estudo de casos múltiplos e empregar as seguintes técnicas para a coleta de dados: entrevista, questionário e pesquisa documental. Suas principais contribuições será apontar as dificuldades encontradas pelas universidades em relação à execução dos convênios firmados com as fundações de apoio à pesquisa. Após 
análise dos fatores que prejudicam a execução e causam devoluções de recursos, a intenção é apresentar possíveis soluções que possam minimizar as dificuldades.

Palavras-chave: Gestão da Informação. Fundações de apoio. Convênios administrativos. Recursos públicos. Agências de Fomento.

\section{INFORMATION MANAGEMENT AGREEMENTS BETWEEN UNIVERSITIES AND RESEARCH SUPPORT FOUNDATIONS}

\section{ABSTRACT}

Faced with a scenario of economic crisis and increasingly scarce funds for education and extension and research projects, this work aims to investigate why Universities return part of the resources coming from agreements signed with research and extension development agencies. Its general objective is to analyze the causes for the return of funds received through agreements, especially from the Public Universities of Paraná with the Araucária Foundation. As for the method, it will be an exploratory qualitative research. It is intended to conduct multiple case studies and employ the following techniques for data collection: interview, questionnaire and documentary research. Its main contributions will be to point out the main difficulties encountered by universities in relation to the execution of the agreements signed with the research support foundations. After analyzing the factors that hinder the execution and cause devolution of resources, the intention is to present possible solutions that can minimize the difficulties.

Keywords: Information Management. Support foundations. Administrative agreements. Public resources. Development Agencies.

\section{INTRODUÇÃO}

No âmbito da Administração pública, convênio é uma forma jurídica por meio da qual se estabelece com outra entidade pública, particulares ou com uma pessoa jurídica de direito privado (associação ou fundação) um ajuste para a consecução de objetivos de interesse comum, mediante mútua colaboração (DI PIETRO, 2009). Um dos convênios comuns de serem firmados é entre as Universidades e as agências de fomento à pesquisa nos diversos estados do país.

As universidades públicas vêm sofrendo cortes nas verbas federais desde 2015. Para agravar o cenário, no primeiro semestre de 2019 houve um contingenciamento do orçamento anual, afetando diretamente as pesquisas e ações de extensão. Ouvia-se muito que as universidades públicas brasileiras estavam à beira de um colapso, pois 
não haveria recursos financeiros suficientes nem para manutenção das atividades básicas, o que faria com que muitas não tivessem como continuar suas atividades. Diante da falta de recursos, as agências de fomento se tornam vitais para o financiamento das pesquisas (OLIVEIRA FILHO et al., 2005).

O Brasil conta com 26 Fundações Estaduais de Amparo à Pesquisa, tais como FAPESP - Fundação de Amparo à Pesquisa no Estado de São Paulo, FAPERGS Fundação de Amparo à Pesquisa no Estado do Rio Grande do Sul, FAPESC - Fundação de Apoio à Pesquisa Científica e Tecnológica do Estado de Santa Catarina, entre outras. No Paraná, tem-se a Fundação Araucária de Apoio ao Desenvolvimento Científico e Tecnológico do Estado do Paraná (FA), cujo objetivo é desenvolver a pesquisa e a inovação no estado. Ela é uma entidade integrante da Administração Indireta do Estado do Paraná, criada por autorização legislativa veiculada na Lei Estadual no 12.020/1998, e faz parte do Conselho Nacional das Fundações de Amparo à Pesquisa (Confap) (FUNDAÇÃO ARAUCÁRIA, 2019a). A Universidade Federal do Paraná (UFPR) e demais universidades públicas do estado frequentemente firmam convênios com esta fundação.

As ações da FA são operacionalizadas por meio de Chamadas Públicas de Projetos (CPs) e Processo de Inexigibilidade de Chamamento Público (PI's) com avaliação de mérito científico feita por pares. Esse trabalho se dá mediante estreita relação com as instituições de ensino superior, sendo: federais, estaduais, municipais e privadas sem fins lucrativos e com institutos de pesquisa do Paraná (FUNDAÇÃO ARAUCÁRIA, 2019b).

A atuação da FA no fomento ao desenvolvimento científico e tecnológico no Estado do Paraná é estruturada em três linhas de ação: a) Fomento à Pesquisa Científica e Tecnológica (e de Inovação); b) Verticalização do Ensino Superior e Formação de Pesquisadores; e c) Disseminação da Pesquisa Científica e Tecnológica (e de Inovação).

Apesar da importância da FA para o desenvolvimento da pesquisa no Estado do Paraná, uma análise breve de dados coletados junto ao TCE-PR revelou que, entre o período de 2013 a 2018, as universidades públicas do Paraná devolveram à FA o 


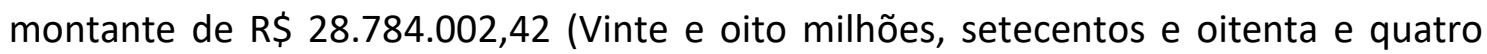
mil, dois reais e quarenta e dois centavos). Conforme dados apresentados no Quadro 1.

Quadro 1 - Devoluções das Universidades públicas paranaenses à FA entre 2013 e 2018

\begin{tabular}{|c|c|c|}
\hline Universidade & $\begin{array}{l}\text { Soma de valor repassado } \\
\text { (R\$) }\end{array}$ & $\begin{array}{l}\text { Soma de devolução } \\
\text { (R\$) }\end{array}$ \\
\hline Universidade 1 & $30.653 .323,00$ & $5.751 .706,30$ \\
\hline Universidade 2 & $34.083 .524,98$ & $7.716 .709,10$ \\
\hline Universidade 3 & $14.925 .789,00$ & $1.903 .478,09$ \\
\hline Universidade 4 & 16.119.174,16 & $1.845 .814,89$ \\
\hline Universidade 5 & $8.095 .932,72$ & $864.001,20$ \\
\hline Universidade 6 & $106.648,00$ & $21.413,28$ \\
\hline Universidade 7 & $36.221,00$ & $11.950,14$ \\
\hline Universidade 8 & $12.413 .054,27$ & $394.602,49$ \\
\hline Universidade 9 & $6.720 .841,43$ & $715.169,19$ \\
\hline Universidade 10 & $225.600,00$ & $18.358,58$ \\
\hline Universidade 11 & $1.853 .407,26$ & $357.062,95$ \\
\hline Universidade 12 & $29.190 .995,81$ & $8.786 .712,20$ \\
\hline Universidade 13 & $23.661,00$ & $1.616,96$ \\
\hline Universidade 14 & $1.411 .321,60$ & $395.407,05$ \\
\hline TOTAL & $155.859 .494,23$ & $28.784 .002,42$ \\
\hline
\end{tabular}

Fonte: Adaptado do TCE-PR (PARANÁ, 2019).

Optou-se por não revelar os nomes das instituições para preservar a identidade. Conforme o quadro 1, a Universidade 12 foi a que apresentou maior valor devolvido, mas, não foi a que mais recebeu recursos. Empiricamente observa-se que ao final da vigência há devolução de um montante significativo de recursos. Em alguns casos, observou-se que há convênios com gasto inferior a 50\% (cinquenta por cento) do valor repassado.

Ao considerar que os convênios representam uma importante e, muitas vezes, indispensável fonte de receita para a manutenção e implementação de atividades relacionadas à pesquisa, cabe a seguinte questão: Por que as universidades devolvem parte dos recursos provenientes de convênios firmados com as instituições de fomento à pesquisa?

Para responder à questão, a pesquisa será delineada a partir de um objetivo geral, sendo: analisar as causas para a devolução dos recursos recebidos via convênios 
com a Fundação Araucária. Para tanto, tem como objetivos específicos: (i) identificar na literatura os desafios para a implantação de convênios; ii) identificar as dificuldades dos coordenadores dos convênios durante a fase de execução; (iii) propor possíveis soluções para a redução do montante de recursos devolvidos à FA.

Esta pesquisa possui uma motivação pessoal, pela percepção de que muitas universidades têm dificuldade de gerir os seus convênios, diante do montante devolvidos à agência de fomento. Têm-se ainda que, as informações sobre os convênios firmados ficam dispersas, prejudicando a sua completude para que permitam uma análise mais aprofundada, de forma a possibilitar a mensuração em relação à execução e eficiência na celebração dos convênios. Do ponto de vista institucional, a pesquisa poderá auxiliar as Universidades em termos de repensar os procedimentos com base na gestão da informação (GI) e conhecimento (GC), e com isso maximizar a utilização dos recursos recebidos via convênios.

Esta proposta de estudo está em consonância com o Programa de PósGraduação em Gestão da Informação (PPGGI) e com a linha de pesquisa Informação e Gestão Organizacional, tendo em vista a análise de questões informacionais, que poderão contribuir para um curso de ação mais eficiente dos recursos da administração pública. Também se considera interdisciplinar, tendo em vista que engloba diferentes áreas de conhecimento, entre elas: Administração, Ciência da Informação e Gestão Pública.

Em relação ao caráter social, os recursos recebidos via FA auxiliam na continuidade dos projetos de pesquisa, sendo importante nas práticas de quem está no meio acadêmico e científico. A otimização dos gastos beneficiará mais pesquisadores. Além disso, a comprovação da eficiência e correta aplicação das verbas dão mais clareza da importância dos projetos e das contribuições trazidas à sociedade. Quanto à contribuição científica, esta pesquisa poderá criar ativos de conhecimento e informação, que produzirão ambientes de aprendizagem, trazendo contribuições significativas às universidades públicas que também façam gestão de convênios. 


\section{FUNDAMENTAÇÃO TEÓRICA}

A fundamentação teórica engloba os seguintes tópicos: a gestão da informação; a gestão da informação no setor público; e convênios com agências de fomento. Estes tópicos serão apresentados a seguir.

A informação é considerada em várias organizações como sendo o fator estrutural e elemento importante para gestão na organização. Dentro de um contexto econômico e social, a função estrutural é considerada como um fator de sucesso para a instituição (MCGEE; PRUSAK, 1994).

As informações existentes precisam ser gerenciadas da mesma forma que os outros recursos existentes na instituição, razão pela qual é necessário o estabelecimento de políticas e estratégias para organização e tratamento de modo que as informações se apresentem com mais eficácia (VALENTIM et al., 2003). A GI é considerada um conjunto de atividades que visam obter necessidades informacionais, mapear fluxos formais de informação, prospectar, coletar, filtrar, monitorar e disseminar informação, no intuito de conseguir utilizá-la nas tarefas diárias e nos processos decisórios dos ambientes organizacionais (VALENTIM, 2008).

Davenport (2000) relata que o fenômeno da Gl ocorre de forma processual, estabelecendo o Modelo Ecológico para o gerenciamento da informação. Este modelo está sustentado no modo holístico de pensar e em quatro atributos-chave: i) integração dos diversos tipos de informação; ii) reconhecimento de mudanças evolutivas; iii) ênfase na observação e na descrição; e iv) ênfase no comportamento pessoal e informacional. Envolve três ambientes: o ambiente informacional que é o centro da abordagem ecológica e abrange seis componentes (estratégia da informação, política da informação, cultura e comportamento em relação à informação, equipe da informação, processos de administração informacional e arquitetura da informação); o ambiente organizacional, que abrange todas as atividades organizacionais, sendo composto: pela situação dos negócios, investimentos em tecnologia e distribuição física; e o ambiente externo, que consiste em informações 
sobre três tópicos fundamentais (mercados de negócios, mercados tecnológicos e mercados da informação).

Na chamada Sociedade da Informação ou do Conhecimento, as informações são essenciais para o processo de tomada de decisão. Santos e Valentim (2014) afirmam que o gerenciamento eficiente dos fluxos informacionais demanda a necessidade de se implantar a GI e a GC para sua efetividade. De acordo com Nassif, Paula e Crivelari (2019), a GI e a GC têm como premissa básica de que a informação é um fator que deve ser devidamente gerenciado para subsidiar às organizações - na figura de seus decisores - a tomar decisão de forma acertada.

As instituições apresentam certas dificuldades no desenvolvimento de ações direcionadas aos fluxos informacionais, e, conforme afirma Starec (2006, p. 51): “[...] as empresas quase sempre têm estratégias para administrar recursos humanos, financeiros ou operacionais, mas poucas têm estratégias definidas para gerir o seu fluxo informacional".

Pereira, Silva e Pinto (2016) afirmam que a informação é reconhecidamente incomensurável e coloca-se cada vez mais o problema da seleção daquela que é pertinente para o trabalho específico, pois a disponibilidade de atenção de cada um é limitada. A questão não é a falta de informação, mas o estabelecimento adequado dos processos de coleta, tratamento, disseminação das informações corretas e relevantes para a solução de problemas organizacionais.

\subsection{GESTÃO DA INFORMAÇÃO NO SETOR PÚBLICO}

Davenport (1998) destaca que a administração pública foi pioneira no desenvolvimento de técnicas de gerenciamento do ciclo da informação, primeiro, como gestão de documentos e depois como gestão da informação. Os governos foram os primeiros a gerenciar informações estruturadas em papel, ainda que assim não se chamasse esta atividade.

Segundo Miranda e Streit (2007), a GI no âmbito do setor público tem como objetivo assegurar que a informação seja administrada de forma efetiva e eficiente 
para promover a qualidade da governança nesse setor. Ainda de acordo com os autores, é possível fazer uma diferenciação do processo de gestão das informações entre as instituições do setor público e as organizações do setor privado. No setor privado, o termo engloba a estrutura e o funcionamento do corpo de diretores e os sistemas de prestação de contas para os acionistas da empresa. Já no setor público, os objetivos e os resultados das transações são menos visíveis e quantificáveis, o poder da direção e controle é mais disperso e os objetivos dos atores são mais variados e muitas vezes conflitantes. Deste modo, a GI nas instituições do setor público assume uma dimensão mais ampla e tem como principais objetivos (i) prestação de contas, mediante a justificativa de decisões e ações, para os que se encontram sob sua jurisdição e público em geral; e, (ii) transparência, mediante fluxo confiável e tempestivo de informações a todos os interessados.

Durante muitos anos a GI foi negligenciada pela Administração Pública, mas sua aplicação no meio ainda é bastante simplória. Embora as instituições públicas, ao contrário das privadas, não trabalhem efetivamente em busca de lucro e diferencial competitivo, elas também precisam acompanhar as mudanças em busca de eficiência, eficácia e efetividade na gestão da coisa pública, apresentando bons resultados à sociedade (BERNARDO et al., 2016).

Miranda e Streit (2007) apontam que os processos de gestão da informação em organizações públicas podem guardar peculiaridades com relação à esfera privada. A organização privada costuma iniciar processos informacionais baseada apenas nas necessidades do seu negócio, já os stakeholders de uma organização pública podem ser todos os cidadãos (pessoas físicas) e, ainda, as pessoas jurídicas que funcionam no país. Os autores ainda mencionam que um processo informacional em uma organização pública pode ser iniciado por diversos motivos: melhorar a efetividade de sua missão; assegurar o acesso (ou a privacidade) de um cidadão ou empresa com relação a determinadas informações de interesse público; prestar contas à sociedade sobre os programas e serviços sob sua responsabilidade; tornar mais transparentes as ações e decisões do governo; preservar os registros sociais, econômicos, e históricos do país; etc. 
Neste contexto a gestão da informação é indispensável na gestão de convênios. Quando uma instituição pública firma convênios com agências de fomento, a gestão destes acaba representando um mecanismo para o controle social - ou seja, a população pode fiscalizar e monitorar a execução dos mesmos.

\subsection{CONVÊNIOS}

Convênio é o acordo, ajuste ou qualquer outro instrumento que discipline a transferência de recursos financeiros de dotações consignadas nos Orçamentos Fiscal e da Seguridade Social da União e tenha como partícipe, de um lado, órgão ou entidade da administração pública federal, direta ou indireta, e, de outro lado, órgão ou entidade da administração pública estadual, distrital ou municipal, direta ou indireta, ou ainda, entidades privadas sem fins lucrativos, visando a execução de programa de governo, envolvendo a realização de projeto, atividade, serviço, aquisição de bens ou evento de interesse recíproco, em regime de mútua cooperação (BRASIL, 2007).

Em relação aos convênios, Leao (2018) afirma que:

eles têm sido, um instrumento importante como fonte de receita para a implementação das atividades das entidades de interesse social. No âmbito da administração pública, muitos programas de fomento acontecem sob a forma de convênios. Os convênios têm natureza de um acordo, colaboração, parceria firmada com outra entidade pública, com particulares ou com uma pessoa jurídica de direito privado (associação ou fundação), com interesses comuns dos partícipes, objetivando o interesse público, sem intenção de lucro (LEAO, 2018, p. 25).

Conforme Magalhães (2012), convênio é o acordo de cooperação celebrado pela Administração, em parceria com a iniciativa privada ou com outros entes estatais, no intuito de buscar o atendimento de finalidades públicas. De acordo com a Lei 8.666/93, nos convênios públicos obrigatoriamente deverá constar os requisitos do $\S 10$, art. 116: 
$\S 1 \mathrm{~A}$ celebração de convênio, acordo ou ajuste pelos órgãos ou entidades da Administração Pública depende de prévia aprovação de competente plano de trabalho proposto pela organização interessada, o qual deverá conter, no mínimo, as seguintes informações:

I- identificação do objeto a ser executado;

II- metas a serem atingidas;

III- etapas ou fases de execução;

IV- plano de aplicação dos recursos financeiros;

V- cronograma de desembolso;

VI- previsão de início e fim da execução do objeto, bem assim da conclusão das etapas ou fases programadas;

De acordo com Palhares (2011), as Fundações de Amparo à Pesquisa (FAPs) têm ganhado muita força nos últimos anos. Não só porque a maioria dos estados brasileiros já tem a sua própria fundação, mas também porque essas agências recebem a cada ano mais recursos, aumentando o seu campo de ação.

Umas das fontes de financiamento das Universidades Federais para execução de suas funções vem dos recursos provenientes de convênios (BARBOSA, 2000 apud DALTO; NOSSA; MARTINEZ, 2014) sendo a segunda maior fonte de recursos (FREITAS et al., 2005 apud DALTO; NOSSA; MARTINEZ, 2014) e representam uma forma de parceria no qual aos partícipes são atribuídas regras rigorosas, no cumprimento dos acordos pactuados com interesses comuns (PECl et al., 2008 apud DALTO; NOSSA; MARTINEZ, 2014). Os valores repassados às entidades privadas para execução de convênio têm a natureza de dinheiro público.

Conforme aponta Azevedo (2014) o convênio precisa observar algumas diretrizes e cita: o alinhamento ao Plano de Trabalho; a relação de itens e relação de equipe executora, aprovados na avaliação de mérito, ou alterados através de solicitações feitas à concedente de recursos; o cumprimento dos prazos de execução física e financeira; as prestações de contas e cumprimento das cláusulas estabelecidas no instrumento contratual. Ressaltando que as atividades de fiscalização, de controle e de prestação de contas são elementos fundamentais nos Convênios. 
Ferreira (2005, p. 15 apud BARBOZA, 2019, p. 94) diz que "[...] a informação agrega valor quando permite à empresa perceber as oportunidades e as ameaças, detectando tendências e problemas". Sendo assim, o valor da informação se dá à medida que sua utilização beneficie as ações da instituição e proceda de forma eficaz ao subsídio das tomadas de decisão, o que vem de encontro com o que aponta Tarapanoff (2015 apud BARBOZA, 2019, p. 94), que "considera a informação como recurso necessário tanto para a identificação do problema quanto para a implementação da solução, por meio de uma análise dos processos organizacionais para compreender e buscar as mudanças requeridas".

\section{PERCURSO METODOLÓGICO}

Para responder à questão de pesquisa, propõe-se realizar um estudo exploratório. De acordo com Prodanov e Freitas (2013), a pesquisa exploratória, quando na fase preliminar tem como finalidade proporcionar mais informações sobre o assunto que vamos investigar, possibilitando sua definição e seu delineamento, isto é, facilitar a delimitação do tema da pesquisa; orientar a fixação dos objetivos e a formulação das hipóteses ou descobrir um novo tipo de enfoque para o assunto. Assume, em geral, as formas de pesquisas bibliográficas e estudos de casos.

Quanto à abordagem, a investigação será qualitativa. Segundo Denzin e Lincoln (2006), a pesquisa qualitativa envolve uma abordagem interpretativa, o que significa que seus pesquisadores estudam as coisas em seus cenários naturais, tentando entender os fenômenos em termos dos significados que as pessoas a eles conferem.

Quanto ao método, pretende-se realizar estudo de casos múltiplos. Estudos de casos são utilizados quando se pretende responder a questionamentos de como e porque, conforme abordado nesta pesquisa (GIL, 2010). O estudo de caso pode ser de caso único ou de casos múltiplos (YIN, 2001). Além disso, o estudo de caso pode estabelecer comparações entre dois ou mais enfoques específicos - Estudos Comparativos de Casos -, ou pode analisar dois ou mais sujeitos sem objetivar compará-los - Estudos Multicasos (TRIVIÑOS, 1987). 
A intenção é selecionar para esta pesquisa ao menos duas universidades que mais devolvem recursos e duas que menos devolvem, com intuito de se fazer comparativos, verificar se os desafios e dificuldades são semelhantes e também identificar o que é feito diferente nas universidades que menos devolvem recursos. A UFPR será uma das universidades selecionadas, por critérios de relevância e oportunidade de aprendizado, além da facilidade de acesso.

Durante a coleta de dados pretende-se empregar as seguintes técnicas: entrevista, questionário e pesquisa documental. Para a identificação dos problemas encontrados pelos coordenadores dos convênios, os meios de coleta dos dados serão estruturados por meio de questionários e/ou entrevistas semi-estruturadas. As entrevistas e questionários serão estendidos aos técnicos administrativos nos casos em que seja identificado que esses auxiliam os coordenadores na execução dos convênios.

Quanto a pesquisa documental, pretende-se investigar os convênios firmados entre a FA e as universidades do Estado do Paraná, que foram encerrados no período de 2013 e 2018. A coleta dos dados relativos à execução financeira será por meio da base do TCE-PR, via portal SIT (Sistema Integrado de Transferência), valendo-se da Lei no 12.527/2011, conhecida como Lei de Acesso à Informação (LAI), que regulamenta o direito, previsto na Constituição, de qualquer pessoa solicitar e receber dos órgãos e entidades públicos, de todos os entes e Poderes, informações públicas por eles produzidas ou custodiadas.

Para a análise dos dados coletados, pretende-se realizar a análise de conteúdo. Bardin (2011) define análise de conteúdo como:

um conjunto de técnicas de análise das comunicações visando a obter, por procedimentos sistemáticos e objetivos de descrição do conteúdo das mensagens, indicadores (quantitativos ou não) que permitam a inferência de conhecimentos relativos às condições de produção/recepção (variáveis inferidas) destas mensagens (BARDIN, 2011, p. 7). 
Para a análise das entrevistas e dos documentos será utilizado o software ATLAS.ti ${ }^{\circledR}$, ferramenta que ajuda na análise de dados qualitativos e que facilitam a interpretação humana e o gerenciamento dos conceitos gerados, sem qualquer automatização do processo de análise. Para análise dos dados coletados por meio dos questionários, estatísticas descritivas poderão ser realizadas para apoiar a pesquisa.

A pesquisa será realizada entre os anos de 2020 e 2021, seguindo o cronograma pré-estabelecido:

Quadro 2 - Cronograma da Pesquisa

\begin{tabular}{|l|c|c|c|c|}
\hline \multicolumn{1}{|c|}{ Etapas } & $\begin{array}{c}\mathbf{1 0} \\
\text { semestre } \\
\mathbf{2 0 2 0}\end{array}$ & $\begin{array}{c}\mathbf{2 0} \\
\text { semestre } \\
\mathbf{2 0 2 0}\end{array}$ & $\begin{array}{c}\mathbf{1 0} \\
\text { semestre } \\
\mathbf{2 0 2 1}\end{array}$ & $\begin{array}{c}\mathbf{2 0} \\
\text { semestre } \\
\mathbf{2 0 2 1}\end{array}$ \\
\hline Aprofundamento teórico & $\mathrm{X}$ & $\mathrm{X}$ & $\mathrm{X}$ & \\
\hline Revisão do projeto de pesquisa & $\mathrm{X}$ & $\mathrm{X}$ & & \\
\hline Coleta de dados & $\mathrm{X}$ & $\mathrm{X}$ & $\mathrm{X}$ & \\
\hline Análise dos dados & $\mathrm{X}$ & $\mathrm{X}$ & $\mathrm{X}$ & \\
\hline Redação da dissertação & & & $\mathrm{X}$ & \\
\hline Qualificação & & & $\mathrm{X}$ & \\
\hline Redação final da dissertação & & & & $\mathrm{X}$ \\
\hline $\begin{array}{l}\text { Finalização da dissertação e entrega para } \\
\text { avaliação da banca }\end{array}$ & & & & $\mathrm{X}$ \\
\hline
\end{tabular}

Fonte: Elaborado pelas autoras (2020)

\section{CONSIDERAÇÕES PARCIAIS}

Percebe-se que a organização e controle da informação na maioria das instituições públicas ainda dá margem a críticas. Como resultado desta pesquisa pretende-se apontar as principais dificuldades encontradas pelas universidades públicas do Paraná em relação à execução dos convênios firmados com as fundações de apoio à pesquisa. Após análise dos fatores que afetam a execução e causam devoluções, a intenção é apresentar possíveis soluções que possam contribuir para que convênios futuros sejam executados com maior êxito.

Esta pesquisa poderá contribuir para uma reflexão acerca do fenômeno relacionado à gestão da informação e ao comportamento informacional no uso das 
fontes de informação nas universidades. Devido a abordagem qualitativa, se espera perceber reflexões em parte dos envolvidos na gestão e execução dos convênios, como uma autoanálise e uma forma diferente de enxergar determinadas situações.

\section{REFERÊNCIAS}

AZEVEDO, Carla Alessandra Rodrigues de Souza de. Prestação de Contas de Convênios com Recursos do FNDCT na Finep: Proposta de Orientações aos Convenentes. 2014. 84 f. Dissertação (Mestrado Profissional em Administração Pública) - Escola Brasileira de Administração Pública e de Empresas, Fundação Getúlio Vargas, Rio de Janeiro, 2014.

BARBOZA, Elder Lopes. Gestão da informação nas organizações e a atuação do profissional da informação. Revista Brasileira de Educação em Ciência da Informação, v.6, n. espec., p. 91-101, abr. 2019. Disponível em:

https://portal.abecin.org.br/rebecin/article/view/103. Acesso em: 13 ago. 2020.

BARDIN, Laurence. Análise de conteúdo. São Paulo: Edições 70, 2011.

BERNARDO, Fabiano Domingos; SILVEIRA, Maria Luiza Gesser; ALBERTON, Luiz; ROSA, Marcelo Medeiros. A Gestão do Conhecimento na Unidade Descentralizada do Serviço de Auditoria do SUS em Santa Catarina. Gestão \& Planejamento, Salvador, v. 17, n. 3, p. 463-479, set./dez. 2016. Disponível em: https://revistas.unifacs.br/index.php/rgb/article/view/3861/3037. Acesso em: 14 out. 2019.

BRASIL. Decreto no 6.170, de 25 de julho de 2007. Dispõe sobre as normas relativas às transferências de recursos da União mediante convênios e contratos de repasse. 2007. Disponível em: http://www.comprasnet.gov.br/legislacao/decretos/De6170_07.htm. Acesso em: 21 nov. 2020.

BRASIL. Lei no 8.666, de 21 de junho de 1993. Regulamenta o art. 37, inciso XXI, da Constituição Federal, institui normas para licitações e contratos da Administração Pública e dá outras providências. 1993. Disponível em:

http://www.planalto.gov.br/ccivil_03/leis//8666cons.htm. Acesso em: 5 jun. 2020.

BRASIL. Lei no 12.527, de 18 de novembro de 2011. Regula o acesso a informações previsto no inciso XXXIII do art. 5으, no inciso II do § 3ㅇ do art. 37 e no $\S 20$ do art. 216 da Constituição Federal; altera a Lei no 8.112, de 11 de dezembro de 1990; revoga a Lei no 11.111, de 5 de maio de 2005, e dispositivos da Lei no 8.159, de 8 de janeiro de 1991; e dá outras providências. Diário Oficial da União, Brasília, DF, 18 nov. 2011. 
DALTO, Crisley do Carmo; NOSSA, Valcemiro; MARTINEZ, Antonio Lopo. Recursos de Convênio entre Fundações de Apoio e Universidades Federais no Brasil: um Estudo dos Acórdãos do Tribunal de Contas da União (TCU). Revista Universo Contábil, Blumenau, v. 10, n. 2, p. 6-23, abr./jun. 2014. Disponível em:

https://proxy.furb.br/ojs/index.php/universocontabil/article/view/3540. Acesso em: 14 jul. 2020.

DAVENPORT, Thomas H. Ecologia da informação. São Paulo: Futura, 1998.

DAVENPORT, Thomas H. Ecologia da informação: por que só a tecnologia não basta para sucesso na era da informação. São Paulo: Futura, 2000.

DENZIN, Norman Kent; LINCOLN, Yvonna Sessions. Introdução: a disciplina e a prática da pesquisa qualitativa. In: DENZIN, Norman Kent; LINCOLN, Yvonna Sessions (org.). 0 planejamento da pesquisa qualitativa: teorias e abordagens. 2. ed. Porto Alegre: Artmed, 2006. p. 15-41.

DI PIETRO, Maria Sylvia Zanella. Direito administrativo. 22. ed. São Paulo: Atlas, 2009.

FUNDAÇÃO ARAUCÁRIA. A Fundação Araucária. Disponível em: http://www.fappr.pr.gov.br/modules/conteudo/conteudo.php?conteudo=3. Acesso em: 8 out. 2019a.

FUNDAÇÃO ARAUCÁRIA. Manual de procedimentos: setores de projetos, convênios e prestação de contas. Disponível em: http://www.fappr.pr.gov.br/ arquivos/File/Arquivos/Manual_de_Procedimentos_FA_Aprovado.pdf. Acesso em: 8 out. 2019b.

GIL, Antonio Carlos. Como elaborar projetos de pesquisa. 5. ed. São Paulo: Atlas, 2010.

LEAO, Ana Cláudia de Andrade Souza. Barreiras na gestão de programas de fomento à pesquisa em uma instituição de saúde pública. 2018. 86 f. Dissertação (Mestrado Profissional em Administração Pública) - Escola Brasileira de Administração Pública e de Empresas, Fundação Getúlio Vargas, Rio de Janeiro, 2018.

MAGALHÃES, Gustavo Alexandre. Convênios Administrativos: Aspectos Polêmicos e análise crítica de seu regime jurídico. São Paulo: Atlas, 2012.

MCGEE, James; PRUSAK, Laurence. Gerenciamento estratégico da informação: aumente a competitividade e a eficiência de sua empresa utilizando a informação como uma ferramenta estratégica. Tradução de: Astrid Beatriz de Figueiredo. 6. ed. Rio de Janeiro: Campus, 1994. 
MIRANDA, Silvania Vieira de; STREIT, Rosalvo Ermes. O processo de gestão da informação em organizações públicas. In: ENCONTRO DE ADMINISTRAÇÃO DA INFORMAÇÃO, 1., 2007, Florianópolis. Anais [...]. Florianópolis: ANPAD, 2007. p. 1-17.

NASSIF, Mônica Erichsen; PAULA, Claudio Paixão Anastácio de; CRIVELLARI, Helena Maria Tarchi. Estudos sobre "Gestão da Informação e do Conhecimento" e "Trabalho" no PPGCl: origens, trajetória e perspectivas futuras. Perspect. ciênc. inf., Belo Horizonte, v. 24, n. spe, p. 102-129, mar. 2019. Disponível em: http://www.scielo.br/scielo.php?script=sci_arttext\&pid=S141399362019000600102\&lng=en\&nrm=iso. Acesso em: 30 nov. 2019.

OLIVEIRA FILHO, Renato Santos de; HOCHMAN, Bernardo; NAHAS, Fabio Xerfan; FERREIRA, Lydia Masako. Fomento à publicação científica e proteção do conhecimento científico. Acta Cir. Bras. [online], v. 20, supl. 2 p. 35-39, 2005. Disponível em: http://www.scielo.br/scielo.php?script=sci_arttext\&pid=S0102$86502005000800009 \&$ Ing=en\&nrm=iso. Acesso em: 20 jun. 2020.

PALHARES, Isabela. Aumento de recursos e articulação propicia ampliação de ações. ComCiência, Campinas, n. 129, 2011. Disponível em: http://comciencia.scielo.br/scielo.php?script=sci_arttext\&pid=S1519$76542011000500004 \&$ Ing=en\&nrm=iso. Acesso em 13 jul. 2020.

PARANÁ. Tribunal de Contas do Estado do Paraná. Quem somos. Disponível em: http://www1.tce.pr.gov.br/conteudo/quem-somos/4/area/45. Acesso em 8 out. 2019.

\section{PRODANOV, Cleber Cristiano; FREITAS, Ernani Cesar. Metodologia do Trabalho}

Científico: Métodos e Técnicas da Pesquisa e do Trabalho Acadêmico. 2. ed. Novo Hamburgo: Universidade Feevale, 2013.

PEREIRA, Maria Olívia Ferreira; SILVA, Helena de Fátima Nunes; PINTO, José Simão de Paula. A Memória organizacional nos processos de gestão do conhecimento: um estudo na Universidade Federal do Paraná. Informação \& Informação, Londrina, v. 21, n. 1, p. 348-374, jan./abr. 2016. Disponível em:

http://www.uel.br/revistas/uel/index.php/informacao/article/view/18253. Acesso em: 1 dez. 2019.

SANTOS, Cássia Dias; VALENTIM, Marta Lígia Pomim. As interconexões entre a gestão da informação e a gestão do conhecimento para o gerenciamento dos fluxos informacionais. Perspectivas em Gestão \& Conhecimento, João Pessoa, v. 4, n. 2, p. 19-33, jul./dez. 2014. Disponível em: http://hdl.handle.net/11449/114790. Acesso em: 30 nov. 2019.

STAREC, Claudio. A dinâmica da informação: a gestão estratégica da informação para a tomada de decisão nas organizações. In: CHAVES, Jorge Bezerra Lopes; STAREC, 
Claudio; GOMES, Elisabeth. Gestão estratégica da informação e inteligência competitiva. São Paulo: Saraiva, 2006. p. 47-66.

TRIVIÑOS, Augusto Nibaldo Silva. Introdução à pesquisa em Ciências Sociais: a pesquisa qualitativa em educação. São Paulo: Atlas, 1987.

VALENTIM, Marta Lígia Pomim; LENZI, Lívia Aparecida Ferreira; CERVANTES, Brígida Maria Nogueira; CARVALHO, Elizabeth Leão de; GARCIA, Heliéte Dominguez; CATARINO, Maria Elizabete; TOMAÉL, Maria Inês. O processo de inteligência competitiva em organizações. DataGramaZero, v. 4, n. 3, jun. 2003. Disponível em: http://hdl.handle.net/20.500.11959/brapci/5453. Acesso em: 20 nov. 2020.

VALENTIM, Marta Lígia Pomim. Gestão da informação e gestão do conhecimento em ambientes organizacionais: conceitos e compreensões. Tendências da Pesquisa Brasileira em Ciência da Informação, v. 1, n. 1, 2008. Disponível em: http://hdl.handle.net/20.500.11959/brapci/119521. Acesso em: 21 nov. 2020.

YIN, Robert K. Estudo de caso: planejamento e métodos. 2. ed. Porto Alegre: Bookman, 2001.

\section{Declaração de Contribuição dos Autores}

Edilaine de Azevedo Vieira - Conceptualização - Curadoria de Dados - Análise Formal Investigação - Metodologia - Administração do Projeto - Validação - Visualização Escrita - Escrita.

Taiane Ritta Coelho - Conceptualização - Metodologia - Administração do Projeto Supervisão - Validação - Visualização - Escrita - Escrita. 